\title{
Learning Styles of African American Children: Instructional Implications
}

\author{
Janice Ellen Hale 1,* $^{*}$ \\ ${ }^{1}$ Founding Director of the Institute for the Study of the African American Child (ISAAC), Professor of Early \\ Childhood Education, Wayne State University, Michigan 48202, USA
}

*Correspondence: 5425 Gullen Mall, Education Building, Room 213, Teacher Education Division, Detroit, Michigan 48202, USA. Tel: 1-248-661-4339. E-mail: janiceehale@cs.com

Received: August 4, 2016

Accepted: September 9, 2016 Online Published: November 24, 2016

doi:10.5430/jct.v5n2p109

URL: http://dx.doi.org/10.5430/jct.v5n2p109

\begin{abstract}
This article offers examples of valiant efforts to develop meaningful instructional implications from learning styles scholarship. Additionally, an example is given of an advance in the public policy arena that merges the efforts of psychological scholars with that of lawmakers to apply their research to effect change for children. The Brown decision was a stellar example in which Lead Attorney Thurgood Marshall and his team were buffeted by the scholarship of Drs. Kenneth and Mamie Clark (1963, 1965). They provided empirical data that documented that the "separate but equal" doctrine of education was psychologically devastating to Negro children. It is recommended that contemporary public policy architects follow in their footsteps.
\end{abstract}

Keywords: African American children; African American education; learning styles and instruction learning styles

\section{Introduction}

It must be borne in mind that the tragedy in life doesn't lie in not reaching your goal. The tragedy lies in having no goal to reach. It isn't a calamity to die with dreams unfulfilled, but it is a calamity not to dream. It is not a disaster to be unable to capture your ideal, but it is a disaster to have no ideal to capture. It is not a disgrace not to reach the stars, but it is a disgrace to have no stars to reach for. Not failure, but low aim is sin.

\section{Dr. Benjamin Elijah Mays}

The Late President Emeritus of

Morehouse College and Mentor to Men

Benjamin Mays, the legendary president of Morehouse College who was a mentor to Dr. Martin Luther King, Jr., wrote a book entitled, Disturbed about man (1969). In that book, Dr. Mays wrote:

It will not be sufficient for Morehouse College, for any college, for that matter to produce clever graduates, men fluent in speech and able to argue their way through, but rather honest men, men who can be trusted in public and private - who are sensitive to the wrongs, the sufferings, and the injustices of society and who are willing to accept responsibility for correcting the ills.

I thought of Dr. Mays' words when I began to review the literature related to cognitive, learning, behavioral, cultural styles of African American children. Elsewhere (Hale, 2016) I have discussed problems in the definition of learning styles; instruments used to measure learning styles; the lack of a cultural theoretical framework; and lack of meaningful instructional implications from learning styles scholarship. In this article, I intend to highlight what has gone right in learning styles applied scholarship as a companion to highlighting what has gone wrong. It is my hope that these examples will stimulate future scholarship in this vein. 
We must continue to develop meaningful instructional implications of learning styles scholarship as we seek to improve the scientific foundation it is based upon - African American children cannot wait. I have identified several studies that represent valiant efforts that should be highlighted. Two studies (Melear and Richardson, 1994; Watkins, 2002) grappled with various stages of moving from theory to hypothesis to the collection of empirical data. Two studies (Diller, 1999; Rowser and Koontz, 1995) made the attempt to go from theory to classroom practice. The article by Diller shares the journey of a white teacher who seeks mentoring in using culturally appropriate pedagogy in her classroom of African American children in the area of literacy. The article by Rowser and Koontz apply Hillard's (1989) cultural styles themes to mathematics instruction. The scholarship of Anderson (1988) and that of McDermott, Piternick, and Rosenquist (1980) provide examples in the discipline of science where cultural themes enhance pedagogy. The scholarship of Coggins, Patrick and Campbell (2008) is highlighted as an example of connecting the cultural perspective to the arena of public policy. It is of critical importance to move beyond arguing among ourselves about who is right and who is wrong to begin to interpret what we know to school districts, legislators and those who make public policy.

Melear and Richardson (1994) created an overlay with the cultural themes identified in my book (Hale, 1982) and collected data corroborating my hypotheses. She collected data in four counties in North Carolina to determine whether the learning styles I described (Hale, 1986) could be identified among African American elementary and high school males through the use of the MBTI. Learning styles differences between the white and African American males were found for children in the $6^{\text {th }}$ and $11^{\text {th }}$ grades. Differences were not found for students above the $12^{\text {th }}$ grade an interpretation is that perhaps those with non-mainstream learning styles may have dropped out by the $12^{\text {th }}$ grade.

Angela Watkins (2002) designed a study to explore empirical validation of the cultural themes of communalism and cooperative learning described in the scholarship in my early work. (Hale, 1982, Hilliard, 1976, Boykin 1983 and others). Her study explored help-seeking behaviors among forty-four 2- to 5 year old African American girls and boys. She coded observed help-seeking behaviors and tallied variable frequencies (source of help, age, type of help solicitation, and kind of activity). Associations between variables were examined.

Her findings demonstrate that preschoolers tend to go to peers in request of academic help. This implies that African American preschoolers are ready and willing to work in cooperative learning structures. The data revealed that children approached teachers more than peers for social help. She also studied the developmental nature of communalism and cooperation at the preschool level for African American children. There was evidence that even though toddlers sought help more than preschoolers, both toddlers and preschoolers tended to approach peers more than teachers for help.

\section{Literacy}

Debbie Diller (1999), a white classroom teacher wrote a very perceptive article in which she drew upon the scholarship in my first book (Hale, 1986) and that of others (Smitherman, 1977; Delpit, 1988, 1992; Strickland, 1994). She identified the points of disconnect between her teaching and the responses of the African American children she taught. She sought mentorship from African American teachers and scholars about the learning styles of the children. She used this mentorship and her observations to identify strategies for teaching to the learning styles of the children in her classroom. She also created new strategies for working with African American parents.

I am highlighting this article because Diller exemplifies the path we need to take as we seek to create the scientific foundation called for in generating this innovative pedagogy. She began by reading the scholarly literature on African American culture and learning styles. She then sought mentorship from friends who were African American teachers. Next, she created a study group within her elementary school building where the learning and cultural styles of the African American children were discussed. She observed in the classrooms of African American teachers who were successful in teaching African American children and recorded their strategies. She attended seminars on vernacular Black English and mastered the fine points of culturally appropriate literacy strategies with African American children. Once she formulated the strategies, she consulted with an African American scholar (Dr. Lisa Delpit) for support, refinement and validation of her strategies. This article is highlighted, not because the strategies are empirically documented. The article is highlighted because of the paths she took in generating them. This odyssey of Diller epitomizes the dynamic collaboration between White and African American teachers and scholars that are needed to push this frontier.

Given the fact that this area of inquiry is in its infancy, we need to capitalize upon the insights of scholars and practitioners to create this dynamic collaboration. 
Among the insights that Diller gleaned from her inquiry were:

1. Cultural discontinuity was identified as a central problem. She observed the mismatch between the culture of the school and the culture of the home. She videotaped her class with the camera focused on the children, not on her as the teacher.

2. Incorporation of multicultural literature in instruction. Her African American teacher/mentors revealed to her that there is a disconnect between African American parents and libraries. This results in under usage of the library in African American communities.

3. The power of speaking to the children "like their mommas do." African American teachers pointed out that African American children like explicit language rather than an inductive, indirect, questioning voice.

4. The children learned best with the comfort and stability of a daily school routine with minimal changes or interruptions.

5. African American teachers recommended the teaching style that parallels the performer style describe in my first book ("Author", 1986) which captured the children's attention.

6. Incorporating the "feel" to learning recommended by African American teachers that incorporate the rhythm, rhyme and movement discussed in my first book ("Author", 1986). She found that the children found delight in chanting and moving to the beat of poetry.

7. She also noticed that the children embraced the cultural themes highlighted in my first book (Hale, 1986) of cooperation and sharing. She noticed that when she structured cooperative learning activities, most of the children appeared to be more engaged. For example, the children observed a spider hanging from their classroom ceiling. They began to research information about spiders. The children became very interested in the topic. Most of the children chose to work with partners to write and share their research on spiders. They enjoyed the support of their classmates.

8. This White teacher became more comfortable talking about race. So, when a child accused her of not liking him because he was Black, she followed Paley's example in White Teacher (1979):

I handled the matter head-on. I held out my hand beside his and said, 'You do have black skin and I have white, but that doesn't mean I don't like you.' I explained that my job was to help each child in our classroom, and that although I sometimes didn't like his actions, I did like him. I gave him examples until he began to giggle. 'I like you because you help other children and show them how to do things. But sometimes you start yelling, and it bothers the other kids who are trying to learn. You need to just tell that old tongue of yours to control itself. You're the only one who can do that. I can't grab your tongue and make it quiet, can I?' Brian never played the race card with me again (p. 824).

9. Absorbed the literature on the situational rules of communication. Through this pathway, she was able to honor the vernacular linguistic culture of African American children while teaching them to code-switch to master mainstream language for success in school and upward mobility.

10. She began to read stories from Taylor and Dorsey-Gaines' (1988) Growing Up Literate. These were stories about families with limited economic resources that provided abundant literacy opportunities for their children. She dismissed her preconception that children of poverty had limited literacy experiences. She began to interview the children about literacy experiences in their homes. They were questioned about favorite books, people who read or told stories to them and about the kinds of activities they did with their families. She compiled the data and planned classroom activities that built upon the information gathered. She found that that the children enjoyed playing cards and games at home with their families, so she included more sight words and spelling words in the format of card games.

An ABC News special report, (Holm, 1993), “Common Miracles: A New Revolution in Education” highlighted innovative schools that had a "games" room. The children played various games so that they could identify the delight they garnered from those activities. The teachers then sought to transfer that enjoyment to engaging in classroom learning activities.

11. She encouraged parents to volunteer in the classrooms. She asked them to read aloud to small groups of children; let them hold hands with the children as they walked to lunch. She noticed that "the children seemed more relaxed when someone who looked like their mother was there to help. They'd sometimes open up and tell the parent helpers things they'd never tell the teacher." 
12. She engaged the parents in telling the teacher about their children outside of school.

13. The parents appreciated having the teacher model reading to their children. The parents appreciated the explicit demonstrations. They admitted that they didn't know the best way to help their child academically and were reluctant to do anything because they didn't want to "mess up" what the schools were doing.

Some African parents told me that they have accents and didn't read to their children because they were afraid their accents would confuse their youngsters. I asked them if they talked to their children with their accents and they said that they did. 'Did your child learn to talk?' I'd ask. They'd smile and realize that they weren't harming their children (p. 828).

14. Her focus was to adapt her teaching rather than try to get the children to change.

She agreed with Shields (1995) that the more teachers acknowledge, respect, and build on the skills, knowledge, language, and behavior patterns that children bring to school, the more likely children will become engaged in academic learning.

15. She agreed with the research that documents the high degree of physical movement on the part of African American children, particularly males. She agreed that it enhanced the achievement of the children when opportunities were provided for active learning. As she experimented with rhythm, rhyme, movement, interactive discussion, cooperative activities in a structured school environment, she began to see many more of the children in her classroom succeed.

\section{Mathematics}

Jacqueline Rowser and Trish Koontz (1995) share my judgment that even though an interest in learning styles blossomed in the 1970's, that scholarship was rarely implemented in the classroom. They suggest that teachers felt that time constraints and other roadblocks made matching a student's cultural learning styles with teaching styles unrealistic. Rowser and Koontz juxtaposed Hilliard's (1976: 38-39) taxonomy of cultural styles with learning activities they observed in classrooms.

\subsection{Many African American Students Tend to Respond in Terms of the Whole Picture Instead of its Parts}

"For example, when studying quadrilaterals, investigate all of the quadrilaterals at the same time, look for similarities and differences instead of studying one shape at a time. A sample introductory lesson follows.

In small groups of two or three students, have students sort the quadrilaterals in figure 1 into two sets. The students must determine the attribute used to sort the shapes. Ask each group to explain how they sorted the shapes into the two sets. Some students will sort by parallel sides or by shapes with right angles. Others will sort by equal sides, by fat and skinny shapes, or perhaps by straight and tilted sides. All of the reasons should be accepted. The idea that shapes can be investigated along many different dimensions is important.

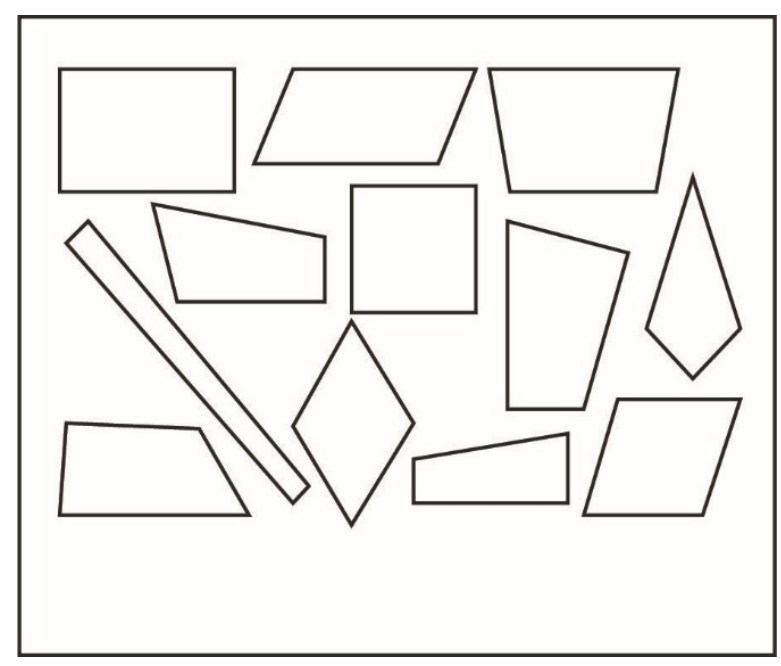

Figure 1. Quadrilaterals to Sort 
Next ask each group to sort the quadrilaterals into three sets: shapes with two pairs of parallel sides, or parallelograms; shapes with only one pair of parallel sides or trapezoids; and shapes with no parallel sides. The students should continue to investigate each subgroup as a whole while looking for specific characteristics by which they could establish another subgroup, as shown in figure 2.

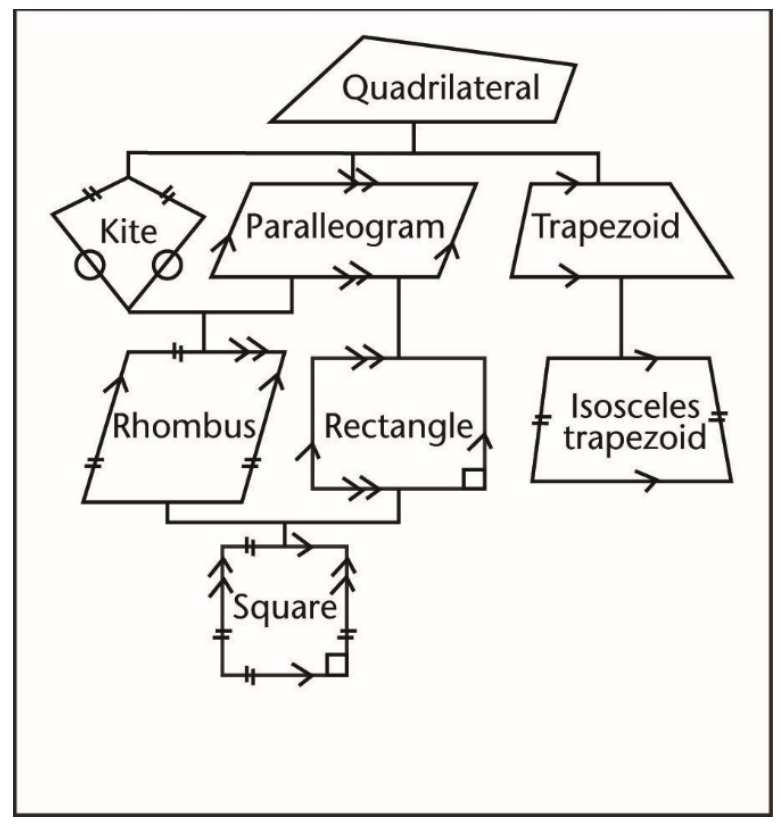

Figure 2. Quadrilaterals Flowchart

\subsection{Many African American Students Tend to Prefer Inferential Reasoning to Deductive Or Inductive Reasoning}

Throughout history, inference has played a vital part in constructing mathematical knowledge and must not be thought of as an inferior way of knowing. According to Joseph (1987: 22-26), it is generally accepted that mathematical discoveries develop only after rigor in deductive axiomatic logic is used. Thus, intuitive or empirical methods are viewed as having little, if any, mathematical value. However, ancient mathematical documents, such as the Moscow Papyrus (c. 1980 B.C.) are considered valid proofs without being symbolic.

An inference is a judgment made from observations or evidence. The evidence, however, can be misleading and can lead to a faulty judgment. For example, a student may infer from a drawing that a triangle is a right triangle when in fact it may not be.

Inductive reasoning forms generalizations from many specific cases. Like inference, the generalizations may not be accurate when the observations are not accurate or when all possible cases have not been studied. An example of faulty inductive reasoning might be the following. After converting a page full of fractions, such as $1 / 2,3 / 4,7 / 8,2 / 5$, and $5 / 8$, into decimals. LeRoy concluded that all fractions can be made into decimals that do not repeat.

Deductive reasoning proceeds from a general statement, includes a specific statement satisfying the hypothesis of the general statement, and then leads to the conclusion. For example, if the perimeter of a square is four inches and a square has four equal sides, then each side is one inch long.

Both deductive and inductive reasoning rely heavily on many pieces of detailed information. Hilliard (1976: 38) points out that the preoccupation with specifics - too many individual details or cases - at the possible loss of a sense of the whole tends to disturb the learning style of many African American students. For these students, the gestalt, not the particular, is often more important. An analogy can be made with teaching writing: teachers stress the importance of expressing the thoughts first before examining details of grammar. Although a need to teach inductive and deductive reason exists, teachers should respect the fact that many African American students approach logic from a different perspective. Inference is an important step in constructing mathematical knowledge. Encourage all students to discuss what they have inferred from models and story lines. Help them reflect on and clarify their inferences by offering an open and accepting environment for all reasoning skills. 


\subsection{Many African American Students Tend to Approximate Space, Number, and Time Rather than Stick to Accuracy}

Generally in the United States, promptness and accuracy are expected. However, in studying mathematics, approximations can be just as important as accuracy. Children, in the past and now, are convinced in school that mathematics is the study of the precise and that only one correct answer and only one correct algorithm are possible.

The National Council of Teachers of Mathematics recommends in the Curriculum and Evaluation Standards for School Mathematics (1989: 37) that children investigate and understand when it is appropriate to estimate and when it is appropriate to calculate an exact answer. If indeed many African American students tend to approximate space, number, and time, teachers need to recognize this approach as an asset, not a deficit. Helping all students recognize that both approximations and precise answers are appropriate depending on the given situation is of utmost importance.

If only exact answers are stressed throughout students' K-12 experiences, then the majority of students would answer the following problem incorrectly. A certain large airplane holds 312 passengers. If 30,316 people want to fly from New York to Paris on this type of airplane, how many airplane trips will be needed to fly all of the people to Paris? In the Mathematics Education Trust's "Testing Using the Calculator Test," over 60 percent of the participants using calculators chose 97.16666 trips as their answer. Teachers need to encourage all students to recognize that an exact answer is not always reasonable.

Primary teachers help children develop number sense in the early years by accepting a response that eight blocks will fit into a box designed to hold ten blocks. The teacher encourages the child by placing the eight blocks in a box and saying, "Yes, eight will fit into the box. Can you find another number of blocks that also might fit? Is a closer fit possible?" Secondary teachers also need to respect approximations as part of number sense. Many secondary students become frustrated with factoring because they have been trained to think that their first guess should be the correct answer. For a student who tends to learn through approximations, a teacher's expectations of exact answers too soon or all the time can create unnecessary frustration. Teachers should discuss with students when and why an approximation is acceptable and when an exact number is necessary. Clearly makes this procedure part of the teaching routine.

\subsection{African American Students Tend to Prefer Novelty, Freedom, and Personal Distinctiveness}

By using a variety of assessments, teachers can better accept alternative forms of expression. For example, mathematics can be applied to art, music, and architecture. By including real-life applications of mathematics, teachers help students make more conceptual connections. Making presentations, writing in journals, building models, and other individual or group assignments can increase interest and success in mathematics by offering students the freedom to express their mathematical knowledge in alternative ways. For example, students should be assigned a data-analysis project requiring them to choose a topic, design the study, collect and analyze the data, and choose appropriate ways to display and report their findings. When students are given the freedom to choose topics important to them, their completed projects will often exceed the teacher's expectations. Students may choose to analyze data about religion, dress, sexual preference, or environmental concerns, to name a few possible topics.

Another project may request that students design a student recreation center. The cost of the building depends on cubic feet of space, materials used, necessary furniture and equipment, labor costs, and other details decided on by the class. Applying many rich geometry and algebra concepts becomes necessary when completing this project. What perimeter of the building makes the largest area? Is floor space directly related to the volume of the structure. Would a three-story building be more economical than a one-floor plan? Is economics always the deciding factor in a design? These two examples give students the freedom to show their individual creativity.

In sum, when teachers become more aware of, and sensitive to the diverse learners in a given classroom, they will be more likely to implement a variety of pedagogical techniques that will enhance learning for all students.

\section{Science}

In the Preface to the $2^{\text {nd }}$ Edition of my first book (Hale, 1986: xv), A call was made for more documentation of the reasons for the success of Black colleges in educating Black students. Such documentation would support the provision of a distinctive educational experience for Black children at earlier ages. The suggestion that African American children would benefit from a culturally congruent post-secondary experience is not as virulently attacked by the educational establishment as the proposal that preschool, elementary, and secondary education should be changed. Presumably, the White establishment doesn't attack the concept that Black colleges produce success with 
African American students because what they do does not affect them. This laissez faire attitude ends when it is suggested that there should be a change in the schools that white children attend. Because the establishment is not as threatened by the documentation of cultural themes that can be found in the success of Historically Black Colleges and Universities (HBCUs), it might be easier to secure funding for such studies. I was told by a White educator that by and large, White parents don't object to African American children receiving a quality education. They just don't want to change the schools as they presently exist to achieve that. The fear is that change might have a deleterious effect on the achievement of White children.

Anderson (1988) points out that the most successful science/pre-medicine programs in the country can be found at Xavier University in New Orleans. Xavier, a historically Black University places more African Americans in medical school than any other university in America. Not only do they place more students who are admitted to medical school, they produce more Black students who graduate and achieve their medical degrees than any other institution. He notes that:

..."the program builds confidence and skill in its predominantly black population by creating an aura of family in which cooperation is highly valued, bonding between the students and faculty is encouraged, and a maintenance of positive ethnic identity is fostered. Learning occurs in a socially reinforcing environment. Incidentally, the director of the program is a white male. One does not have to be the same race/ethnicity to identify and capitalize upon the cultural/cognitive assets of minority populations." (p. 8)

Included in this discussion should also be the legendary dual degree program in Business Administration at Florida A\&M University that was created by Dr. Sybil Collins Mobley. The Florida A\&M University (FAMU) School of Business and Industry (SBI), under the leadership of the founding dean, Dr. Sybil Collins Mobley, was established in 1974 to prepare talented students from around the nation and the world to not only survive, but to thrive in a competitive global market place. Nearly four decades later, the outstanding record of SBI's achievements is known worldwide, especially among corporate executives and recruiters who frequently visit SBI to observe and review its academic, professional development and internship programs as well as to recruit SBI students. Tom Peters, in his bestselling book, A Passion for Excellence,(1984), described SBI as "the Marine corps of business schools: pride, poise, excellence!"

Anderson (1988) points out further that African American students encounter problems when they attempt to adapt to the theoretical, often abstract reasoning process that is utilized in mathematics and the hard sciences. Most courses in both math and science teach the theory of the discipline in an abstract sense before the student is exposed to the practical applications in laboratory exercises. This has always been the sequence of training in mathematics and science and coincides with the Anglo-European cognitive style, especially that of males. The approach of giving students direct experience with applications of formal concepts and laws is not as valued and utilized as much by teachers. I cannot help but interject here that when I attended high school in an inner city, defacto segregated school, no laboratory experiences were provided in biology. My first exposure to a biological lab was as a freshman at Spelman College. So, even if a teacher wanted to put a laboratory experience first, there was no opportunity to do so.

McDermott, Piternick, and Rosenquist (1980) found such an approach to be extremely successful in helping minority students succeed in physics and biology at the University of Washington. Brown (1986) at the University of San Diego found that the same approach worked in her mathematics lab.

\section{Public Policy Arena: Thurgood Marshall Needed Kenneth Clark - Brown Decision 1954}

There is a law in Florida, The African and African American History Law (Florida Statute 233.061 [1] [f] ) that creates a fiduciary obligation and requires that African American History be infused into all courses and at all grade levels from PreK-12 in all Florida public schools. All elected officials (school board members, legislators, superintendents) as well as other educators are obligated to ensure that the spirit and intent of this law are carried out. This obligation extends to those in higher education to design teacher training programs that can implement the courses in the classrooms in which they teach. I would like to know who the legislative team was in the Florida State Legislature that designed and passed this legislation. One of the realities of life in America is that legislation and litigation has not had the intended results when applied to changing inequities affecting Black children (Brown v. the Board of Education 1954 and countless other legal decisions, including the 1972 decision of the Supreme Court to desegregate the public schools). Legislation that is intended to oppress the aspirations and fortunes of African Americans is enforced, such as Plessey v. Ferguson (1896) that legalized "separate but equal." 
There was an interesting occurrence when the African American Community Coalition of Palm Beach, Florida requested that the Palm Beach County School Board incorporate African and African American History into the curriculum used in the Palm Beach County public schools. A school board member, Dr. Art Johnson, in response to the Coalition's request, said that unless the Coalition could provide research showing that the teaching of African and African American History would enhance student performance in language arts and other subject areas, he would not support the request for incorporating it into the curriculum. This is interesting, given the fact that this was a state law. Apparently, this white public official felt that the enforcement of laws related to African Americans is discretionary.

A study conducted by Coggins and Campbell (2008) was prepared at the request of the Coalition to perform the requested research and prepare a response to Dr. Johnson's stipulation. The focus of this scholarship was in the area of multicultural education and focused on the following three premises:

1. Teaching about the achievements of African Americans enhances student literacy and achievement in schools;

2. Multicultural Education can be taught successfully to all students;

3. Minority students including African Americans benefit from the instruction of curriculum that reflects their history (p. 48).

This article is not presented as an "end all and be all" solution. Communities have to move on what they can "wrap their arms around." Lobbying for "multicultural education" is a starting point that has value in the education of African American children. However, it is not the totality of changes that are needed in the education of African American children. This article is highlighted as an example of the manner in which scholars need to connect with parents and community activists to supply architects of public policy with the tools they need to effect change. The Brown decision was a stellar example in which Lead Attorney Thurgood Marshall and his team were buffeted by the scholarship of Drs. Kenneth and Mamie Clarke $(1963,1965)$. They provided empirical data that document that the "separate but equal" doctrine of education was psychologically devastating to Negro children. As we push for the science, we have to also become active in the public policy arena.

\section{Conclusion}

There is a need for scholars to create a solid foundation for culturally appropriate pedagogies by strengthening the science on which those instructional strategies are based. Additionally, every school district has statistical and evaluation experts who crunch numbers and quantify the "achievement gap". However, without a grounding in the cultural nuances of those data, no effective implications for educational policy will emerge. Though educational entities may have data, when there is no culturally appropriate interpretation of the achievement data and patterns, there is no subsequent creation of effective remedies and interventions - only hand wringing.

A simple example of the barriers for school districts and other collectors of data that prevent them from creating solutions is in the fact that many report data by ethnic group and by gender but not typically by ethnic group by gender. That is, they can divide data between males and females in one data set. They can also give you a breakdown of achievement by grade level and by ethnic group. In this author's work as a consultant with school districts in closing the achievement gap that affects African American children, the data comparing African American males and females was not readily available and difficult to access. There is inadequate insight on the part of school district evaluation specialists that data on African American children must be disaggregated by gender to determine the extent to which low performance should be attributed to African American males or females at different grade levels and in each subject matter area. This disaggregation is essential to understanding the achievement gap and in designing interventions. Additionally, the empirical literature demonstrates that African American males, compared to females, are at particular risk for low educational achievement (Davis, 2003).

Another example in the same vein was the low performance of African American students on $8^{\text {th }}$ grade mathematics proficiency exams. This writer raised the issue of where the children of various ethnic groups were in the progression of mathematics courses when they took the $8^{\text {th }}$ grade exam. In consultation with teachers, it was revealed that the majority of the African American students were taking $8^{\text {th }}$ grade basic math whereas the White students who were outperforming them were significantly more likely to be enrolled in Algebra I, Geometry and even Algebra II in the $8^{\text {th }}$ grade.

The recommendations for future research are implicit in the article. Numerous references are made to the learning styles of African American children in scholarly articles (Durodoye, 1995; Williams, 1998; Berry, 2003; Moody, 
2004; Parsons, 2005; Cantrell, 2006; Emeka, 2006; Bailey, 2007; Carter, 2008; Wright, 2011; Duskins, 2012;). This article advocates that scholars take the time to strengthen the science that undergirds scholarship on the learning styles of African American children.

\section{References}

Anderson, J.A. (1988). Cognitive styles and multicultural populations. Journal of Teacher Education, 29, 2-9. https://doi.org/10.1177/002248718803900102

Bailey, L. (2007). The development of cultural congruence in relation to African American student Achievement. 3268130 Temple University. Ann Arbor: ProQuest Dissertations \& Theses.

Berry, R. (2003). Mathematics standards, cultural styles and learning preferences: The plight and Promise of African American students. Clearing House, 78(5), 244-249. https://doi.org/10.1080/00098650309602013

Boykin, A. W. (1983). On academic task performance and Afro American children. In J.R. Spencer (Ed.), Achievement and achievement motives. Albany, NY: State University of New York Press. (pp. 324 -371).

Brown, M. (1986). Calculus by the dozen: A retention program for undergraduate minority Students in mathematics based majors. A paper presented at the second annual Conference On Black Student Retention, Atlanta, Georgia, November.

Cantrell, C. (2006). Learning style characteristics and learning activity preferences of African-American adult learners in rehabilitation counseling master of science programs. 3256989 University of Northern Colorado. Ann Arbor: ProQuest Dissertations and Theses.

Carter, N. (2008). The relationship between verve and the academic achievement of African American students in reading and mathematics in an urban middle school. Educational Foundations, 22(1/2), 29-46.

Clarke, K. (1963). Education Stimulation of Racially Disadvantaged Children. In A. H. Passover (Ed.), Education in Depressed Areas. New York: Teachers College, Columbia.

Clarke, K. (1965). Dark Ghetto: Dilemma of Social Power. New York: Harper and Row.

Coggins, P., \& Campbell, S. (2008). Using cultural competence to close the achievement gap. The Journal of Pan African Studies, 2(4), 44-59.

Davis, J. E. (2003). Early schooling and academic achievement of African American males. Urban Education, 38(5), 515-537. https://doi.org/10.1177/0042085903256220

Delpit, L. (1988). The silenced dialogue: Power and pedagogy in educating other people's children in Harvard Education Review, 58, 280-298.

Delpit, L. (1992). Education in a multicultural society: Our future's greatest challenge. Journal of Negro Education, 61, 237-249. https://doi.org/10.2307/2295245

Diller, D.. (1999). Opening the dialogue: Using culture as a tool in teaching young African American children. The Reading Teacher, 52(8), 820-829.

Durodoye, B. (1995). Learning styles and the African American student. Education, 116(2), 241-255.

Duskins, G. (2012). Culture and learning style: A perspective on African American school children's written literacies. Proceedings from National Association of African American Studies. Scarborough, pages 392-411.

Emeka, V. (2006). No Child Left Behind? An Analysis of the No Child Left Behind Act of 2001 and the relevance of cultural frameworks in its implementation for underachieving African American students. 3212960 Loyola University Chicago. Ann Arbor: Proquest Dissertations \& Theses.

Hale, J.E. (1982). Black children: Their roots, culture and learning styles. Baltimore, MD: The Johns Hopkins University Press.

Hale, J.E. (1986). Black children: Their roots culture and learning styles. Baltimore, MD: The Johns Hopkins University Press, Revised Edition.

Hale, J.E. (2016). Thirty Year Retrospective on the Learning Styles of African American Children. Education and Urban Society, 48(5), 20.

Hilliard, A. (1976). Alternatives to I.Q. testing: An approach to identifying gifted minority children. Final Report to 
the California State Board of Education.

Hilliard, A. (1989). Teachers and cultural styles in a pluralistic society in NEA today: A newspaper for members of the National Education Association, 7(6), 59-69.

Holm, S. (1993). Common miracles: A new revolution in education (A special Report that was broadcast on the Evening news). New York, NY: American Broadcasting Company.

Joseph, G. (1987). Foundations of Eurocentrism in mathematics. Race and Class, 37, 13-28.

Mays, B. (1969). Disturbed about man. Louisville, Kentucky: John Knox Press.

McDermott, L., Piternick, L., \& Rosenquist, M. (1980). Helping minority students succeed in science. Journal of College Student Teaching, 10(1), 135-140.

Melear, C., \& Richardson, S. (1994). Learning Styles of African American children which correspond to the MBTL. ERIC document ED368794.

Moody, V. (2004). Sociocultural orientations and the mathematical success of African American students. Journal of Educational Research, 97(3), 135-146. https://doi.org/10.3200/JOER.97.3.135-146

National Council of Teachers of Mathematics. (1989). Curriculum and evaluation standards For school mathematics - An agenda for action. Reston, VA.: National Council for Teachers of Mathematics.

Paley, V. (1979). White teacher. Cambridge, MA: Harvard University Press.

Parsons, E. (2005). The Black cultural ethos: Students' instructional context preferences, and student achievement: An examination of culturally congruent science instruction in the eighth grade classes of one African American and one Euro-American teacher. Negro Educational Review, 56(2/3), 183-203.

Peters, T., \& Austin, N. (1984). A Passion for Excellence: The Leadership Difference. London: Harper Collins Business.

Plessy v Ferguson 163 U.S. 537 (1896). Jurisdiction: United States of America, Supreme Court Date of Decision: 18 May 1896; Case Status: Concluded. Link to full text: Retrieved from http://caselaw.lp.findlaw.com/scripts/getcase.pl?court=US\&vol=163\&invol=537

Rowser, J., \& Koontz, T. (1995). Inclusion of African American Students in Mathematics Classrooms: Issues of Style, Curriculum and Expectations. The Mathematics Teacher, 88(6), 448-453.

Shields, P. M. (1995). Engaging children of diverse backgrounds. In M.S. Knapp (Ed.), Teaching for meaning in high-poverty classrooms (pp. 33-46). New York: Teacher's College Press.

Smitherman, G. (1977). Talkin' and testifying: The language of Black America. Detroit, Michigan: Wayne State University Press.

Strickland, D. (1994). Educating African American learners at risk: Finding a better way. Language Arts, 71, 328-336.

Taylor, D., \& Dorsey-Gaines, C. (1988). Growing up literate: Learning from inner city families. Portsmouth, NH: Heineman.

Watkins, A. (2002). Learning styles of African American children: A developmental consideration. Journal of Black Psychology, 28(3), 3-17.

White, S. (1992). Factors that contribute to learning differences among African American and Caucasian students. ERIC document ED374177.

Williams, J. (1998). Effective urban elementary classrooms: A look at culture, styles of learning and effective teaching practices for African American children. 9826729 University of Massachusetts Lowell. Ann Arbor: ProQuest Dissertations and Theses. 